\title{
SOEP
}

SOEPpapers

SOEPpapers
on Multidisciplinary Panel Data Research

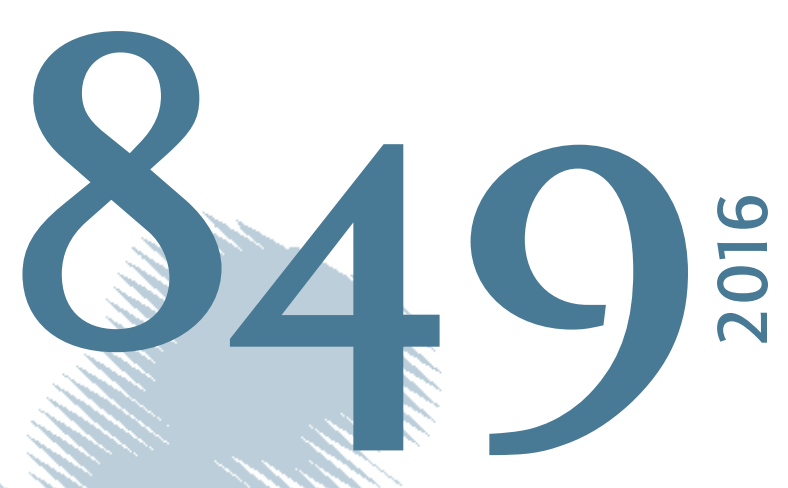

\section{Leisure and Housing Consumption after Retirement: New Evidence on the Life-Cycle Hypothesis}


This series presents research findings based either directly on data from the German SocioEconomic Panel study (SOEP) or using SOEP data as part of an internationally comparable data set (e.g. CNEF, ECHP, LIS, LWS, CHER/PACO). SOEP is a truly multidisciplinary household panel study covering a wide range of social and behavioral sciences: economics, sociology, psychology, survey methodology, econometrics and applied statistics, educational science, political science, public health, behavioral genetics, demography, geography, and sport science.

The decision to publish a submission in SOEPpapers is made by a board of editors chosen by the DIW Berlin to represent the wide range of disciplines covered by SOEP. There is no external referee process and papers are either accepted or rejected without revision. Papers appear in this series as works in progress and may also appear elsewhere. They often represent preliminary studies and are circulated to encourage discussion. Citation of such a paper should account for its provisional character. A revised version may be requested from the author directly.

Any opinions expressed in this series are those of the author(s) and not those of DIW Berlin. Research disseminated by DIW Berlin may include views on public policy issues, but the institute itself takes no institutional policy positions.

The SOEPpapers are available at http://www.diw.de/soeppapers

\section{Editors:}

Jan Goebel (Spatial Economics)

Martin Kroh (Political Science, Survey Methodology)

Carsten Schröder (Public Economics)

Jürgen Schupp (Sociology)

Conchita D'Ambrosio (Public Economics, DIW Research Fellow)

Denis Gerstorf (Psychology, DIW Research Director)

Elke Holst (Gender Studies, DIW Research Director)

Frauke Kreuter (Survey Methodology, DIW Research Fellow)

Frieder R. Lang (Psychology, DIW Research Fellow)

Jörg-Peter Schräpler (Survey Methodology, DIW Research Fellow)

Thomas Siedler (Empirical Economics)

C. Katharina Spieß ( Education and Family Economics)

Gert G. Wagner (Social Sciences)

ISSN: 1864-6689 (online)

German Socio-Economic Panel (SOEP)

DIW Berlin

Mohrenstrasse 58

10117 Berlin, Germany

Contact: Uta Rahmann | soeppapers@diw.de

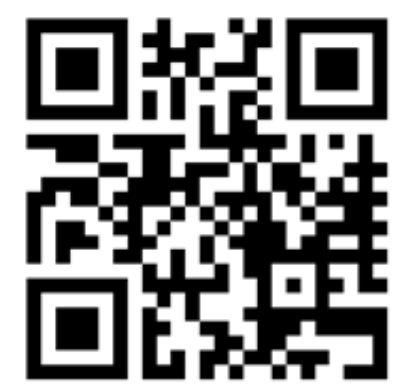




\title{
Leisure and Housing Consumption after
}

\section{Retirement: New Evidence on the Life-Cycle Hypothesis*}

\author{
by Sven Schreiber and Miriam Beblo ${ }^{\dagger}$
}

this version: May 2016

\begin{abstract}
We revisit the alleged retirement consumption puzzle. According to the life-cycle theory, foreseeable income reductions such as those around retirement should not affect consumption. However, we first recall that given higher leisure endowments after retirement, the theory does predict a fall of total market consumption expenditures. In order not to mistake this predicted drop for a puzzle we focus on housing consumption which can be plausibly regarded as complementary to leisure, and we control for the leisure change in our empirical specifications, using micro data for Germany (SOEP), where housing expenditures are observable as rents for the majority $(60 \%)$, as well as dwelling relocations. We still find significant negative impacts of the retirement status on housing consumption, which is hard to reconcile with the life-cycle theory. For retirees we also find significant effects of the income reduction at retirement on housing. However, the effects are small in quantitative terms, given the lock-in nature of past housing decisions.
\end{abstract}

Keywords: consumption smoothing, retirement-consumption puzzle, SOEP

JEL codes: D91 (Intertemporal Consumer Choice; Life Cycle Models and Saving), E21 (Consumption; Saving; Wealth)

${ }^{*}$ We thank Aunt Ingrid for (unknowingly) inspiring this paper. We also thank seminar participants at the IMK, Free University Berlin, the MEA SAVE conference, the Econometric Society World Congress, University Magdeburg, University Paris 1 Panthéon-Sorbonne, and the European Economic Association meeting for helpful comments, especially Viktor Steiner and Michael Hurd.

${ }^{\dagger}$ Beblo: University of Hamburg, miriam.beblo@wiso.uni-hamburg.de; Schreiber (corresponding author): Macroeconomic Policy Institute Düsseldorf (IMK) at Hans Boeckler Foundation, and Free University Berlin, svetosch@gmx.net, fax +49-211-7778-4596.

${ }^{\ddagger}$ Earlier versions of this paper have been circulated already in 2010 under a different title, but given the rare-event nature of our study in the restricted relevant SOEP sample we had to wait for more panel waves to appear. The theoretical section has also been sharpened, and the overall role of leisure has been made explicit. 


\section{Introduction}

Do people save too little? Or more precisely, do they undersave compared to the benchmark prediction of the standard life-cycle model? (Modigliani and Brumberg, 1954; Friedman, 1957) Undersaving would mean that people are unable to smooth their consumption paths according to the permanent-income hypothesis of consumption and saving, ${ }^{1}$ and "the best evidence of undersaving is probably the observation that, upon retirement, individuals, on average, reduce consumption substantially." (Akerlof, 2002, p. 424) That is the so-called retirement-consumption puzzle. Since the consumption function is a central building block of most (macro-) economic models, it is a fundamentally important issue whether the standard lifecycle model provides a good approximation to reality or not. By conducting a new test of the consumption-smoothing hypothesis we contribute to the literature on whether the life-cycle theory of consumption is valid in general. The novelty of our approach revolves around our focus on housing consumption and explicitly taking into account the discontinuous increase of available leisure time. ${ }^{2}$ First, these expenditures cannot be substituted by the increased leisure after retirement (see below). Second, we exploit the fact that the majority of the German population do not own their homes, which means (a) that their housing expenditures are directly observable as rents paid, and (b) that they are potentially more prone to the undersaving problem due to the absence of housing wealth.

There is no consensus in the economic literature on the existence of a retirementconsumption puzzle, and the debate is still ongoing. On the one hand, there is the position that "retired people are commonly believed to tailor their consumption to a concept of income rather than to the value of their assets." (Akerlof, 2007, p. 18) Banks, Blundell, and Tanner (1998) conclude after analyzing UK micro data: “We argue that the only way to reconcile fully the fall in consumption with the life-cycle hypothesis is with the systematic arrival of unexpected adverse information." This

\footnotetext{
${ }^{1}$ Of course consumption smoothing may still imply rising or falling consumption paths given differentials between personal time discount rates and net (after-tax) interest rates, but discrete and sudden jumps are ruled out.

${ }^{2}$ The influence of hours worked (the labor market status) on consumption can be traced back at least to Heckman (1974). Some parts of that insight seem to have been lost over the years and are not always found in the recent literature, however.
} 
finding would at least reject the life-cycle-cum-rational-expectations strong form of the model, since "systematic" and "unexpected" together are incompatible with rational expectations. Bernheim, Skinner, and Weinberg (2001) also reject life-cycle models in favor of rule-of-thumb or mental-accounting savings behavior. Benartzi and Thaler (2007) cite broad evidence that the standard model fails. ${ }^{3}$

On the other hand there is an important opposing strand of the literature which argues that extended models of optimizing and forward-looking behavior are compatible with the empirical observations, see also Hurst (2008) for a survey, and Hurd and Rohwedder (2008) for associating changes in consumption with these arguments.

First and perhaps most fundamentally, Aguila, Attanasio, and Meghir (2011) do not find any expenditure drop after retirement at all for non-durable consumption goods, using micro panel data for the US. A very similar result for German expenditure survey data was found by Beznoska and Steiner (2012). However, taken at face value these broad constancy findings would constitute a puzzle in the opposite direction, as we will argue in the theory section below. Scholz, Seshadri, and Khitatrakun (2006) claim that the household-specific predictions from an optimizing model with a realistic account of the environment are close to observed wealth values; however, still $20 \%$ of households hold less wealth than would be prescribed by the optimal decision model.

Second, the increased possibility of substituting market purchases through home production of goods has been addressed repeatedly in the literature. Baxter and Jermann (1999) found that allowing for home production explains the apparent excess sensitivity of consumption to income that would otherwise invalidate the permanent-income hypothesis. Aguiar and Hurst (2005) find "dramatically" rising time use on home production which substitutes for example the drop in expenditures on food, such that food consumption stays roughly unchanged for retirees. With German SOEP panel data Schwerdt (2005) finds a positive correlation between consumption reductions at retirement and (proxies for) home production,

\footnotetext{
${ }^{3}$ The retirement-consumption puzzle is just one manifestation of the general (alleged) excess sensitivity of consumption to current income. For evidence on this phenomenon see for example Campbell and Mankiw (1990); Attanasio and Browning (1995); Reis (2006).
} 
but he argues that not all of the fall of consumption can be attributed to that effect, because there is a general rise in home production. Recently Lührmann (2010) refined those findings for Germany by combining both consumer expenditures and time use data pre and post retirement. She reveals a significant drop in expenses at retirement which coincides with an increase in time spent on home production.

In order to circumvent the problem of measuring home production (whether it rises and if so, by enough to substitute the consumption drop), we focus on housing. Housing cannot be substituted by home production, indeed it will usually be a complement to the increased leisure time budget in the utility functions of individuals. The German institutional (and possibly cultural) environment is well suited for our analysis because Germany is a country where less than half of all households own their homes. This has the advantage that housing expenditures are directly observable for many households as rents paid. For this reason we analyze only non-home owners. Obviously this implies that our results will not be (necessarily) representative for all individuals. Indeed, it is plausible that home owners suffer much less from the under-saving problem precisely because of their owned house or apartment, which represents cumulated savings. However, since the life-cycle model is a hypothesis relating to all economic agents, focusing on a suitable sub-group is still an informative approach.

Our main result is that we indeed find that (negative) income growth at (foreseeable) retirement helps to explain a reduction of housing consumption. Therefore our test rejects the life-cycle model of consumption as a generally valid theory of economic behavior. However, the effect is not large even for our subgroup of non-homeowners which may explain the ambiguous conclusions in the existing literature. The leisure change mainly serves as a control variable, but in our given samples it does not have a significant influence on housing consumption, which by itself is compatible with our theoretical framework.

In the next section we make explicit the theoretical background for housing consumption in a stylized life-cycle model that incorporates leisure explicitly. The dataset is introduced and some descriptive evidence is given in Section 3. Section 4 presents and discusses the estimation results and Section 5 concludes. 


\section{Theory}

\subsection{A benchmark framework}

To fix ideas, let us outline a version of the permanent-income hypothesis that is extended to explicitly include leisure in the utility function. Each household $i$ faces the following utility maximization problem from current period $t$ up to the end of the life cycle $T_{i}:{ }^{4}$

$$
\max _{\left\{v_{i, t+j}\right\}_{j=0}^{T_{i}}} \mathbb{E}_{t} \sum_{j=0}^{T_{i}} \beta^{j} u\left(v_{i, t+j}\right)
$$

where $\beta<1$ is the time discount factor, $v_{i, t}=\left(s_{i, t}, k_{i, t}, l_{i, t}\right)^{\prime}$ is the vector of arguments entering the utility function, the part $c_{i, t}=s_{i, t}+k_{i, t}$ represents real expenditures on market consumption goods and $l_{i, t}$ is the amount of leisure in any period $t$. For our purposes it is useful to differentiate between two components of the consumption basket according to their utility properties with respect to leisure: $s_{i, t}$ denotes the amount of goods consumed by household $i$ which are (partial) substitutes of leisure, and $k_{i, t}$ are those goods that are partial complements to leisure. Below we will clarify how housing consumption $h_{i, t}$ is related to the inputs of the utility function $v_{i, t}$.

The standard intertemporal budget constraint that the household faces in period $t$ is given by

$$
\mathbb{E}_{t} \sum_{j=0}^{T_{i}}\left(1+r_{t+j}\right)^{-j} c_{i, t+j} \leq A_{i, t}+\mathbb{E}_{t} \sum_{j=0}^{T_{i}}\left(1+r_{t+j}\right)^{-j} y_{i, t+j}
$$

where $r_{t+j}$ is the relevant market interest rate, $A_{i, t}$ is initial wealth, and $y_{i, t+j}$ denotes future income. In the following we abstract from interest rate fluctuations and use a constant $r$ or even abstract from discounting altogether. The fact that the budget constraint spans the entire life cycle means that liquidity or borrowing constraints

\footnotetext{
${ }^{4}$ Here we do not analyze the intra-household allocation or decision problem explicitly. See Lundberg, Startz, and Stillman (2003) for the scope of bargaining models in this context or Stancanelli and Van Soest (2012) for spouses' joint retirement decisions. For simplicity we also ignore a nondeterministic end of the life cycle. Finally, we could in principle treat all parameters as householdspecific with an additional index $i$, but in the empirical part we make the standard assumption of homogeneous coefficients except for household-specific fixed effects. Therefore we abstract from individual heterogeneity here for notational simplicity.
} 
are also ignored. ${ }^{5}$ For leisure consumption in each period there is a natural upper bound $l_{i, t} \leq \bar{l}$ of how many potential hours there are in the day.

Because we do not address issues of risk and volatility we may choose a quadratic specification with certainty equivalence for the instantaneous utility function $u\left(v_{i, t}\right)$ :

$$
u\left(v_{i, t}\right)=z+a^{\prime} v_{i, t}+v_{i, t}^{\prime} Q v_{i, t}
$$

where $z$ is a constant and $a$ is a three-dimensional coefficient vector, while $Q$ is a symmetric and negative-definite matrix such that $u$ is concave (diminishing marginal returns).

The vector of marginal utilities is given by

$$
\frac{\partial u\left(v_{i, t}\right)}{\partial v_{i, t}}=a+2\left[\begin{array}{ccc}
q_{s s} & & \\
q_{s k} & q_{k k} & \\
q_{s l} & q_{k l} & q_{l l}
\end{array}\right] v_{i, t}
$$

such that the marginal utilities are $a+2 Q v_{i, t}$ which are required to be positive (nonsatiation). The second-order derivatives are then obtained as

$$
\frac{\partial^{2} u\left(v_{i, t}\right)}{\partial v_{i, t} \partial v_{i, t}^{\prime}}=2 Q
$$

Negative-definiteness of $Q$ in particular implies that all entries on the diagonal must be negative, $q_{s s}, q_{k k}, q_{l l}<0$, and that $q_{n n} q_{m m}-q_{n m}^{2}>0$ for all $n, m \in\{s, k, l\}$. Intuitively, the cross effects $q_{s k}, q_{k l}, q_{s l}$ must not be too large.

Our assumptions about the substitution and complementarity relations between the consumption components and leisure are then formally reflected as follows.

- $q_{s l}<0$ : The consumption component $s_{i, t}$ is a (partial) substitute of leisure $l_{i, t}$ for the typical household $i$.

\footnotetext{
${ }^{5}$ One of the leading explanations for departures from the LCH is liquidity constraints. However, this argument is based on the inability to borrow against higher income later in life. Thus it applies very little to agents at an advanced age. If those agents had been constrained at a young age this merely means that on average their consumption later in life was inefficiently high compared to the ex-ante optimum. The presence of earlier liquidity constraints has no bearing on the change at retirement.
} 
- $q_{k l}>0$ : The component $k_{i, t}$ is complementary to $l_{i, t}$.

- The remaining entry $q_{s k}$ reflecting the partial relationship between $s_{i, t}$ and $k_{i, t}$ is not restricted.

One of the main hypotheses in this paper is that the consumption of housing services should be complementary to leisure, because intuitively each euro spent on housing provides more utility if you have more time to spend at your home. According to this hypothesis, housing consumption $h_{i, t}$ constitutes a part of $k_{i, t}$, and the corresponding utility cross effect with respect to leisure would be positive ( $q_{k l}>$ $0){ }^{6}$

The permanent-income hypothesis is usually formulated in terms of monetary expenditures on goods and services, and in that world permanent income would amount to the sum of initial wealth and the present value of all future monetary income streams, distributed as an annuity over the remaining life cycle. The result is that current consumption should be equal to (the annuity value of) permanent income. An implication is that in the absence of unexpected shocks the consumption profile would be smooth, no matter how volatile the expected income developments are.

However, agents really seek to smooth (expected) utility, and the consumption smoothing result relates to consumption in a broad sense, capturing everything that enters the utility function. In our case we have leisure as an additional argument in $u()$, and thus the life-cycle model of consumption does not necessarily imply that expenditures on consumption goods and services $c$ would also be smoothed. Instead the optimal path of $c$ and its components $s$ and $k$ also depend on the path of $l$.

\footnotetext{
${ }^{6}$ For expositional purposes we treat $k_{i, t}$ as homogeneous in its utility effect. In general of course the utility coefficients of the housing component would likely be different from the non-housing parts of $k_{i, t}$. However, the central hypothesis here is that the cross effects of any components of $k_{i, t}$, including housing $h_{i, t}$, are positive with respect to $l_{i, t}$.
} 


\subsection{Effects of leisure changes at retirement}

In particular we focus on the retirement event where $l$ is subject to a large positive shift, and the occurrence of the event is largely determined by institutional rules. ${ }^{7}$ At retirement we typically have $\Delta y_{i, t}<0$ and $\Delta l_{i, t}>0$, but the drop in current income alone should not have an effect, because it is expected for a forward-looking and informed household (in the absence of liquidity or borrowing constraints). However, the equally expected but unavoidable rise of leisure would raise utility, and since a discontinuous shift of the expected utility level cannot be optimal it is clear that the rational reaction at retirement would be $\Delta c_{i, t}<0$. This effect can be interpreted as an endowment effect which exists in addition to the production substitution effect, where the extra free time is used as a factor of production to crowd out market purchases of food or similar items (home production).

This drop in expenditures at retirement creates a positive correlation between current income and expenditure levels which could be mistaken for the famous retirement-consumption puzzle but in fact would be a result of life-cycle theory. Indeed, many analyses of the retirement consumption puzzle have tended to ignore this issue. As we elaborate formally in this section, a drop in total consumption is not sufficient to falsify the life-cycle theory. The reverse direction is also problematic, however. Contrary to the standard interpretation, empirical demonstrations as in Aguila, Attanasio, and Meghir (2011) that consumption around retirement is constant would actually mean that households react non-optimally and would not be compatible with the life-cycle model, at least under the maintained assumption that leisure is a positive factor of overall utility.

However, even if $\Delta c_{i, t}<0$ at retirement, this does not necessarily mean that both consumption components $s_{i, t}$ and $k_{i, t}$ would fall. Instead this depends on the details of the preferences. Let us therefore provide a stylized but concrete formalization of the situation at retirement. For simplicity we abstract from discounting,

\footnotetext{
${ }^{7}$ We do not literally claim that the timing is exogenous for all workers. In fact, in Germany it is possible to choose the retirement age within certain limits. However, retiring prematurely (which is different from a formerly existing possibility labeled early retirement -Vorruhestand) in Germany entails pension cuts, and most workers do not find it attractive. So we treat the retirement event as exogenous in that sense, leaving workers a focal option they typically do not refuse.
} 
and we assume that the units of leisure are chosen such that its monetary valuation matches the overall price level for market goods and services. Then the life-time income in a broad sense is given by

$$
I=\sum_{t=1}^{T_{i}}\left(y_{i, t}+l_{i, t}\right),
$$

and the corresponding annuity value for the current period is $\bar{i}=T_{i}^{-1} I$. The flow budget constraint for the utility maximization problem can then be written as:

$$
s_{i, t}+k_{i, t}+l_{i, t} \leq \bar{i}
$$

Furthermore we abstract here from labor supply decisions such that the paths of $y_{i, t}$ and $l_{i, t}$ are treated as exogenous. We denote this exogeneity with $l_{i, t}=\bar{l}_{i, t}$. The flow utility maximization problem is then given by:

$$
\begin{aligned}
\max _{s_{i, t}, k_{i, t}} u_{i, t}\left(\bar{v}_{i, t}\right) & =z+a^{\prime} \bar{v}_{i, t}+\bar{v}_{i, t}^{\prime} Q \bar{v}_{i, t}, \\
\text { s.t. } & s_{i, t}+k_{i, t}+\bar{l}_{i, t} \leq \bar{i}
\end{aligned}
$$

where $\bar{v}_{i, t}=\left(s_{i, t}, k_{i, t}, \bar{l}_{i, t}\right)$. Of course the budget constraint (4) will hold with equality and we can substitute out one of the choice variables, for example $k_{i, t}=\bar{i}-\bar{l}_{i, t}-s_{i, t}$. We obtain the following simple maximization problem:

$$
\begin{array}{cl}
\max _{s_{i, t}} & z+a_{s} s_{i, t}+a_{k}\left(\bar{i}-\bar{l}_{i, t}-s_{i, t}\right)+a_{l} \bar{l}_{i, t}+q_{s s} s_{i, t}^{2}+q_{k k}\left(\bar{i}-\bar{l}_{i, t}-s_{i, t}\right)^{2}+q_{l l} \bar{l}_{i, t}^{2} \\
& +2 q_{s k} s_{i, t}\left(\bar{i}-\bar{l}_{i, t}-s_{i, t}\right)+2 q_{s l} s_{i, t} \bar{l}_{i, t}+2 q_{k l}\left(\bar{i}-\bar{l}_{i, t}-s_{i, t}\right) \bar{l}_{i, t}
\end{array}
$$

The FOC yields:

$$
s_{i, t}^{*}=\frac{0.5\left(a_{k}-a_{s}\right)+\bar{i}\left(q_{k k}-q_{s k}\right)+\bar{l}_{i, t}\left(q_{k l}+q_{s k}-q_{s l}-q_{k k}\right)}{q_{s s}+q_{k k}-2 q_{s k}}
$$

In addition, the SOC requires that $q_{s s}+q_{k k}-2 q_{s k}<0$ for a maximum, or $q_{s k}>$ $0.5\left(q_{s s}+q_{k k}\right)$, which means that the cross utility effect between substitutive goods $s$ and complementary goods $k$ must be positive or smaller in absolute value than 
the average of the own effects of $s$ and $k$.

The budget constraint $s_{i, t}^{*}+k_{i, t}^{*}+\bar{l}_{i, t}=\bar{i}$ means that $d\left(s_{i, t}^{*}+k_{i, t}^{*}\right) / d \bar{l}_{i, t}=-1=$ $d c_{i, t}^{*} / d \bar{l}_{i, t}$. This implies that at least one of the components must be reduced. The question is how the reduction in goods consumption is distributed between $s_{i, t}$ and $k_{i, t}$. The effect of an (exogenous) change of the leisure amount $\bar{l}_{i, t}$ on the optimal consumption of the leisure-substitute component $s_{i, t}^{*}$ is given by:

$$
\frac{d s_{i, t}^{*}}{d \bar{l}_{i, t}}=\frac{q_{k l}+q_{s k}-q_{s l}-q_{k k}}{q_{s s}+q_{k k}-2 q_{s k}}
$$

Because the denominator is negative by the SOC, the expression (5) is negative if $q_{s k}>q_{k k}+q_{s l}-q_{k l}$. Since the latter right-hand side expression is necessarily negative, a sufficient (but not necessary) condition is that $q_{s k} \geq 0$. Another sufficient condition would be that $q_{s s} \geq q_{k k}$, because in combination with the SOC this would imply $q_{s k} \geq q_{k k}>q_{k k}+q_{s l}-q_{k l}$. Therefore, while negativity of (5) cannot be strictly guaranteed, it would seem quite likely.

According to the relationship $k_{i, t}=\bar{i}-\bar{l}_{i, t}-s_{i, t}$ the change of $s_{i, t}^{*}$ translates into the change of $k_{i, t}^{*}$ as

$$
\frac{d k_{i, t}^{*}}{d \bar{l}_{i, t}}=-1-\frac{d s_{i, t}^{*}}{d \bar{l}_{i, t}}
$$

Intuitively, the reaction of the substitutive good $s$ should be stronger than that of the complementary good $k$, or $d s_{i, t}^{*} / d \bar{l}_{i, t}<-0.5<d k_{i, t}^{*} / d \bar{l}_{i, t}$. Comparing (5) and (6) leads to the condition:

$$
\left|q_{s s}\right|<0.5\left(\left|q_{k k}\right|+\left|q_{s s}\right|\right)+\left|q_{s l}\right|+\left|q_{k l}\right|
$$

For a stronger reaction of the substitutive good the own partial effect of $s$ on (diminishing) marginal utilities must not be too high, relative to the own effect of $k$ and the cross effects originating from $l$. The same sufficient condition as before would apply here, namely $q_{s s} \geq q_{k k}\left(\left|q_{s s}\right| \leq\left|q_{k k}\right|\right)$. Again, condition (7) is not automatically fulfilled in this class of utility functions, but appears very likely to hold in practice. Therefore we assume that it holds.

Given that the reactions of $s$ and $k$ must add to -1 , it could also be the case 
that $d k_{i, t}^{*} / d \bar{l}_{i, t}>0$ (and thus $d s_{i, t}^{*} / d \bar{l}_{i, t}<-1$ ), such that the reaction of $k$ would be positive. This is the case if:

$$
q_{s k}<q_{s s}+q_{k l}-q_{s l}
$$

The right-hand side expression in (8) can be positive or negative in general and therefore the sign of $q_{s k}$ alone does not provide a definite answer. Also, notice that in the special case $q_{s s}+2\left(\left|q_{k l}\right|+\left|q_{s l}\right|\right)<q_{k k}$, the required negativity of (5) would rule out (8).

Summing up, optimizing intertemporal behavior requires that total consumption of goods and services is reduced given an exogenous increase of leisure, as happens around retirement. Furthermore it is likely (although not guaranteed) that the consumption of leisure-complementary goods is reduced less than that of leisure substitutes. Depending on the details of preferences, complementary goods and services -including housing- might even be consumed more instead of less.

It is important to recognize that these reactions would happen in response to the rise in leisure, not because of the drop in income. Therefore, after controlling for the leisure change the expected income change at retirement should not have an effect, as in the traditional formulation of the life-cycle hypothesis without leisure.

\subsection{Confounding effects}

After presenting our stylized life-cycle framework with leisure and before moving on to the empirical analysis, let us discuss in a less formal way other (fully rational) influences that could play a role for housing consumption changes around retirement.

For example, the search for a new home could be so costly in terms of forgone leisure that it is optimal to postpone it until after retirement, when leisure is not scarce anymore. Contrary to the effect in Section 2.2 this would just be an indirect working of the leisure change, not a direct utility-based influence. However, it would still be controlled for by including a measure of leisure, thus it remains true that the observed income change should not have an effect conditional on these controls. Only the effect of the leisure variable might be confounded. On the other 
hand, our sample is deliberately restricted to men beyond the age of 55 whose children are typically not very time-demanding of their parents anymore. Note also that the typical amount of hours worked per year is quite a bit lower in Germany than for example in the US. Therefore it seems somewhat implausible that forgone leisure should inhibit people from searching for a cheaper home. Finally, people may hire agents; in Germany those are usually only paid in case of a successful match.

Next, workers are geographically bound to some extent by the location of their workplace. They are only free to move away when they retire, and housing might be cheaper for example in rural areas farther away from economic centers. A cheaper home then might not necessarily imply a reduction of the utility value of the home compared to the old one in a more expensive location, such that there would be a mismeasurement. In this case the observed move should then indeed lead to a sufficiently different geographical location. In our available dataset we cannot fully observe the geographical change, but this effect should be independent of the income change amount. Instead it would be reflected only in the retirement status dummy. ${ }^{8}$

Finally, in the case of "early" retirement, the income drop might actually be unexpected, and no consumption smoothing would then be rationally expected. A distinction between anticipated and unanticipated changes is empirically important according to Blau (2008), Haider and Stephens (2007), or Smith (2006). Therefore we control for the early retirement event, but after the 1990s this policy was not used much anymore in Germany.

If we depart from fully rational explanations, there are many potentially relevant behavioral economic hypotheses. For example, the existence of norms and/or mental accounting could mean that for an agent her current income is like an entitlement to spend or "norm"-al in the literal sense (Shefrin and Thaler, 1988). This would imply a dependence of (housing) consumption on current income, after taking into account lock-in effects that would weaken the correlation. Or it could be

\footnotetext{
${ }^{8} \mathrm{~A}$ pragmatic issue is that more detailed geographical information in the SOEP is subject to certain usage restrictions. Future research could possibly incorporate such an analysis.
} 
that agents procrastinate: they might be perfectly aware that they should rationally be moving to a cheaper home, but they do not act accordingly ( $\mathrm{O}^{\prime}$ Donoghue and Rabin, 1999). This explanation in isolation would imply that agents used to have a good reason to live in their expensive home. The most likely case is the space requirement of children. Finally, another simple explanation is myopia, i.e. the assumption that agents simply do not consider their future needs. In its extreme form that would imply that no income changes ever lead to an adjustment of current consumption until wealth is depleted. In general, myopia of course induces undersaving and tends to prevent wealth accumulation.

Note that contrary to widespread conception the assumption of hyperbolic discounting (present bias) alone is not sufficient to generate an excess sensitivity of consumption to current income, as pointed out for example in Akerlof (2007, fn 39) by invoking the analogy to Barro's well-known model with bequests (Barro, 1974): The future selves of an individual in a model with hyperbolic discounting effectively take the role of the heirs in the dynastic model. Also, in a "golden-eggs" model a la Laibson (1997) a rational agent with hyperbolic discounting preferences (and who knows about her time inconsistent preferences) will invest in illiquid assets to avoid temptation in the future. Effectively such an agent makes her future selves liquidity-constrained. A rational agent with hyperbolic discounting would therefore have invested in assets with a corresponding duration (time to maturity). ${ }^{9}$ Thus she would be able to smooth her cash flow and hence her consumption expenditures.

\section{Dataset and descriptive evidence}

\subsection{SOEP}

To investigate the housing consumption behavior of people entering retirement we draw on panel data of the German Socio-Economic Panel (SOEP, 2013). The SOEP is a yearly micro-data panel which has been conducted in annual interviews of

\footnotetext{
${ }^{9}$ In developed countries such as Germany those types of assets clearly exist and are quite widespread; for example so-called "capital life insurance" contracts which are essentially savings plans that pay an annuity or a lump-sum payment after retirement.
} 
individuals and households since 1984 in West Germany and since 1990 in East Germany. It is well suited for our analysis as it contains detailed information on both the retirement and the housing issues. From wave to wave respondents report whether they have changed their employment status because of retirement and whether they have moved to another apartment, including rental costs before and after. Respondents also provide information about their household size, income and other living circumstances. Moreover, this information is available over a long period of time which enables us to gather a decent number of respondents who actually enter retirement within the observation period. One drawback, however, is the fact that household wealth levels are not provided in the SOEP, nor is total consumption available (and by consequence also no current savings).

Despite the many advantages of longitudinal data, panel attrition may be a particular problem when studying moving behavior. According to the official documentation, panel attrition in the SOEP, related to households that were lost after they moved to unknown new addresses, is roughly $0.5 \%$ on average each year (Kroh, 2009). If it does have any effect on our results at all, this attrition is expected to bias our findings in the direction of the life-cycle hypothesis.

\subsection{Sample selection}

Due to some inconsistency in the wording of the SOEP questionnaires before 1993, the retirement event cannot be deduced correctly, so we start with the panel wave 1994 (i.e. $t-1$ starts at 1993). The latest wave we use refers to 2012. Given a massive rent catch-up in East Germany from constrained levels in the years after unification, we leave out East German observations before 1997.

As we want to compare the housing behavior of recently retired workers with other individuals (or households), we do not restrict the sample to those going into retirement. Nevertheless, in order to obtain a relatively homogeneous sample we include men between the ages of 55 and 75 , centered around the standard nominal retirement age of 65 .

An important feature of our analysis is that we focus on home tenants, thus excluding home owners. The main reason for this exclusion is that the current cost 
of housing is unobservable for non-tenants. But it is clear that home owners tend to stay in their apartments or houses after retirement. In general their behavior is probably consistent with the life-cycle hypothesis to a larger extent than the behavior of tenants, because the asset of a home itself constitutes a considerable savings item for retirement. Therefore we acknowledge that in our setup we would find non-consumption-smoothing results more easily than in a representative sample of the whole population. If we find violations of the life-cycle hypothesis, this finding might then not apply to the roughly $40 \%$ of the households in the SOEP who are home owners.

The number of observations along the time dimension is of course different for each cross-sectional unit. Due to the fact that some variables are constructed as first time differences or lags we lose one observation in the time dimension for each unit.

\subsection{Descriptive evidence}

First of all we document the plausible fact that the amount of available leisure increases substantially around retirement. The leisure time use information is gleaned from a set of items in the SOEP questionnaire in which respondents are asked to report the average amount of time per day spent on employment (including travel time to and from work), errands (shopping, errands, citizen's duties), housework (washing, cooking, cleaning), childcare, other care activities (only since 2001), education or further training, repairs on and around the house, car repairs, garden work, as well as hobbies and other free-time activities. Since we regard leisure time as a rather broad category of one's disposable time, our leisure variable is calculated as the residual of a day's 24 hours and the individual time uses reported (except education and hobbies). On an annual basis, hours are available for weekdays only (weekends are reported bi-annually). For this reason, we focus on weekday time use.

Since a small number of respondents report simultaneous activities totalling more than 24 hours per day, we restrict the sum of all work activities to 18 hours per day (thereby requiring at least 6 hours of physical rest on average). Employmentrelated time is taken as reported, and the remaining time uses are scaled down 
proportionately if they exceed the upper bound.

Figure 1 reports both the distribution of changes for the subsample of retirers as well as the separate distributions of the leisure levels for non-retired and retired men, respectively. The mode of the change distribution appears around 8 hours which would correspond to a standard full-time job.

The next fundamental fact consists of the reduction of current income after retirement, displayed in Figure 2. Here it is interesting that the mode occurs just barely below zero. Only few households experience income drops below $-35 \%$, which is plausible given the replacement rates prevailing in the German pension system for those cohorts. It is also interesting that a sizable part of the observations displays rising income. As we consider household income, this increase may stem from life insurance contracts that become due or a rising income of the spouse. Hence, it could be the case that there is a different puzzle reflected in those observations, namely the possibility that many people in Germany even have saved too much for old age, given the relatively high level of state-provided old-age pensions and health care benefits, compared to countries like the US. However, that aspect is beyond the scope of this paper.

One advantage of the SOEP data is that it provides rents paid by tenant households that we can use as a direct housing cost measure. Analogously to the leisure and income changes of retirers we report in Figure 3 the distribution of rent growth. The median is negative around $-3 \%$, but because of the skewness the mean growth rate is positive around $7 \%$. Because of the high variance it is not clear from this univariate distribution whether the retirement event determines the location of the housing consumption growth variable.

Apart from the measurement of housing costs in the form of rents, we will also use the following binary variables extracted or constructed from the information in the SOEP in order to analyze the housing consumption decision:

- $m_{i, t}^{c o}($ "move_cost"): Whether respondents answered "for cost reasons" as the main reason for moving. This information is only available in the SOEP from 1997 onwards. Out of all 874 observed moving events, $m_{i, t}^{c o}=1$ in 128 cases 

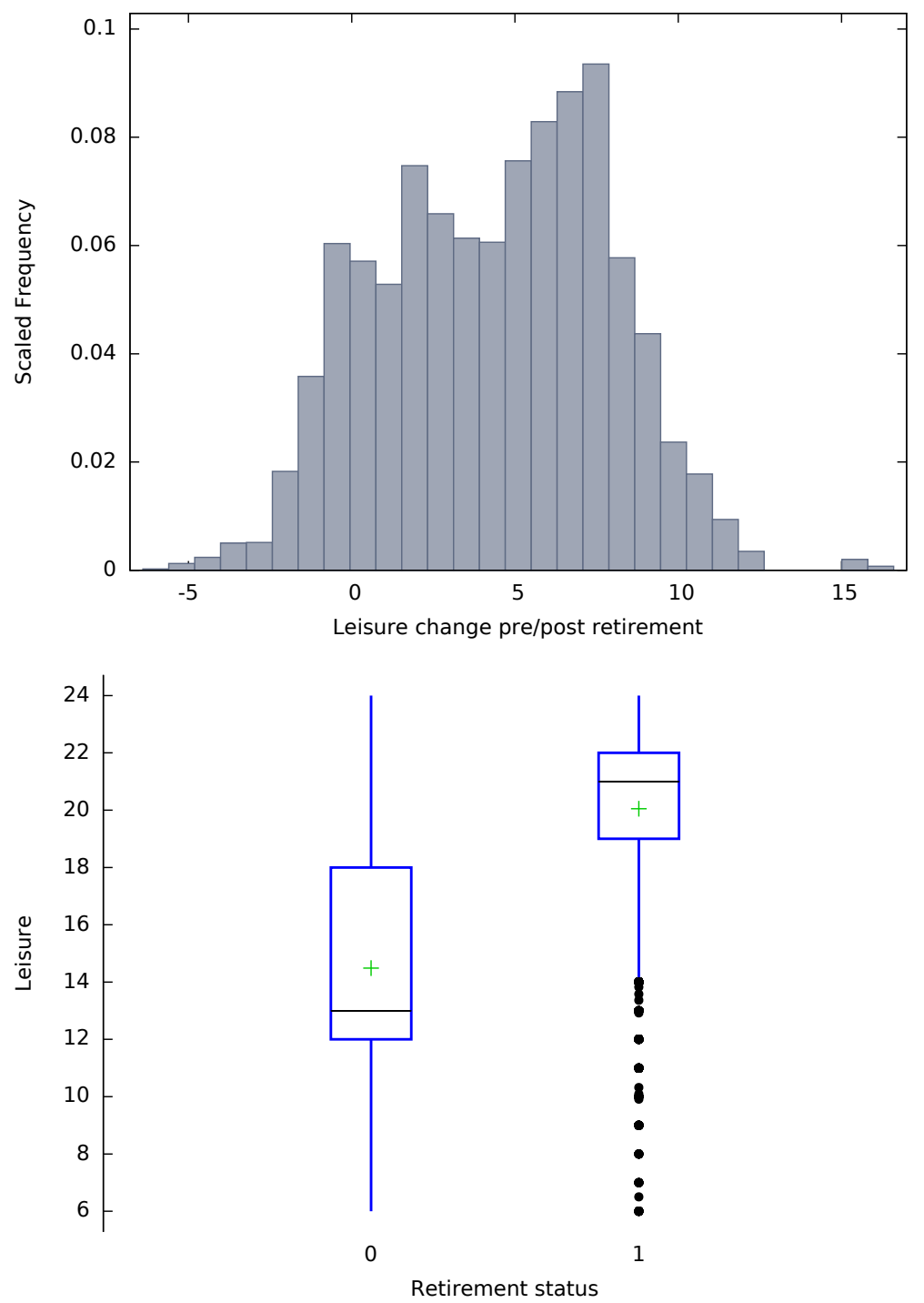

Figure 1: Leisure rise at retirement. Upper panel: Distribution of average leisure change for those male household heads with an observed retirement event (in daily hours). Lower panel: Boxplots of the distributions of all observations, conditional on the retirement status. 


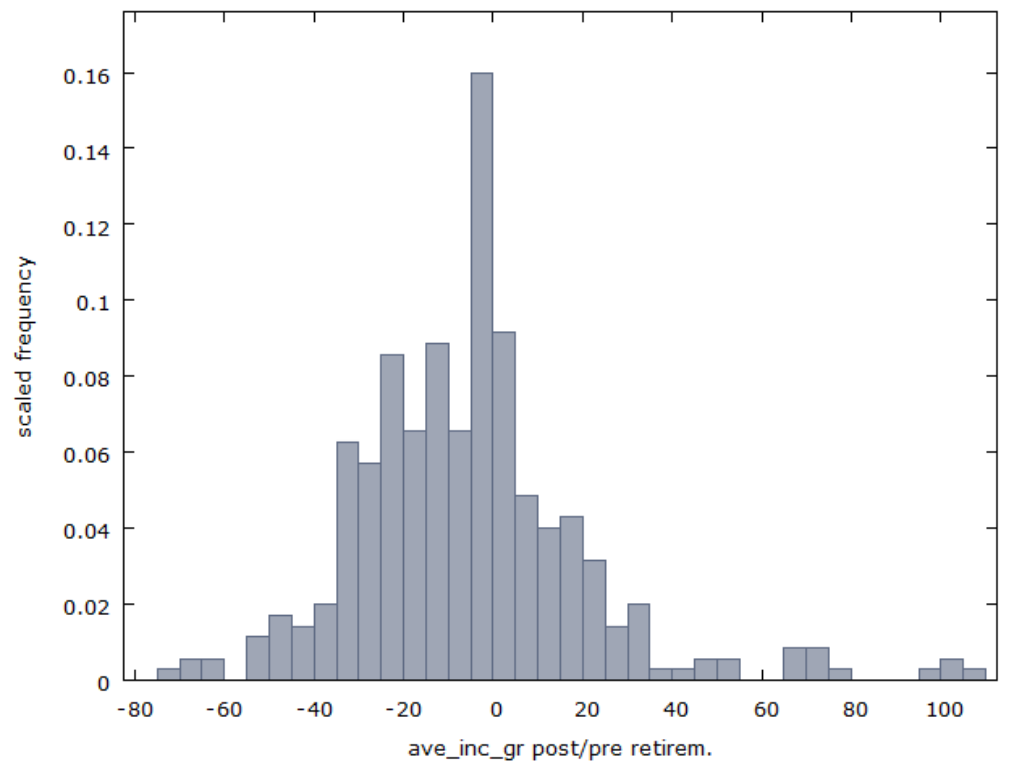

Figure 2: Income drop at retirement. Distribution of average real post-retirement income level relative to pre-retirement level, per household, expressed as a growth rate in percentages.

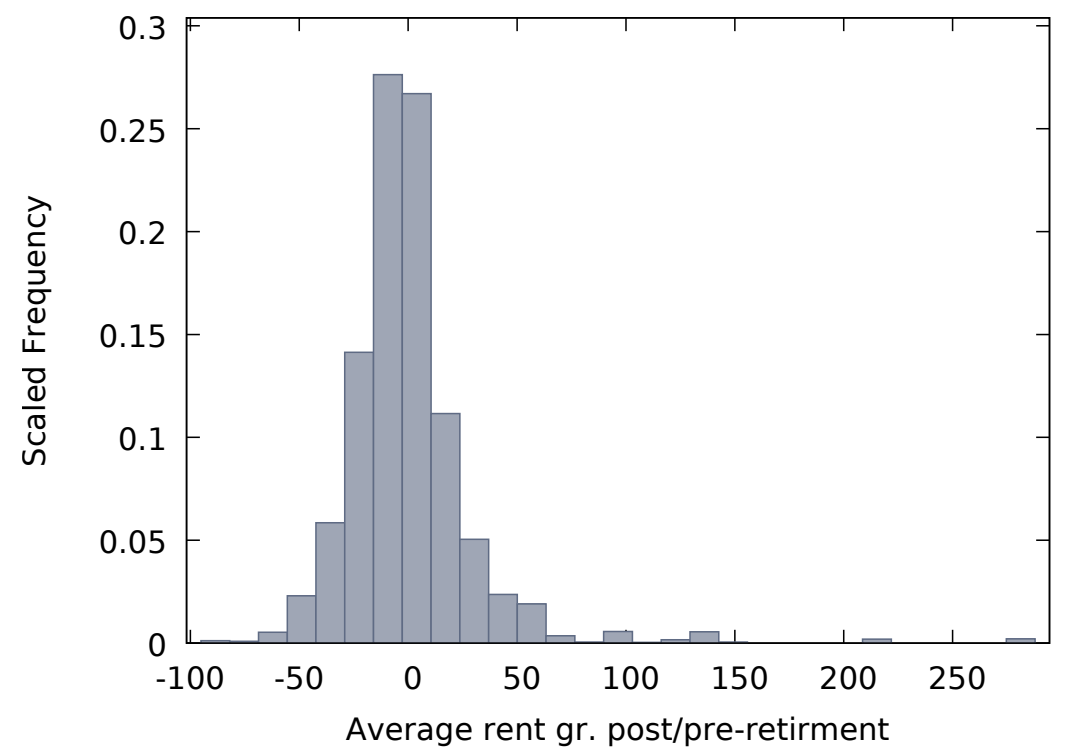

Figure 3: Housing rent changes at retirement. Distribution of average real postretirement rent level relative to pre-retirement level, per household, expressed as a growth rate in percentages. 
Table 1: Events moving to cheaper home $\left(m_{i, t}^{c h}\right)$ vs. moving for cost reasons $\left(m_{i, t}^{c o}\right)$

\begin{tabular}{ccccc}
\hline & & \multicolumn{3}{c}{ move_cheaper } \\
& & 0 & 1 & Total \\
\hline \multirow{3}{*}{ move_cost } & 0 & 14598 & 194 & 14792 \\
& 1 & 23 & 84 & 107 \\
\cline { 2 - 5 } & Total & 14621 & 278 & 14899 \\
\hline
\end{tabular}

$(15 \%)$.

- $m_{i, t}^{\text {ch }}$ ("move_cheaper"): Whether or not a move to a cheaper home took place. The information about the move event is given in the SOEP. The new home is considered cheaper if $\Delta r_{i, t}$ is negative (the growth rate / log-difference between this year's and last year's rent paid). Out of the 708 observed moving events, ${ }^{10} 292$ lead to a cheaper home (41\%)

In Table 1 we compare the incidence of these binary variables in the common subsample where both are available. Indeed, in $70 \%$ of the lower rent cases (194 / 278) the respondents do not give priority to the cost argument, while in the majority of moving-for-cost-reason cases $(84 / 107,79 \%)$ they do cut housing expenses. Therefore the two variables are correlated but are not perfect substitutes.

\section{Specifications and estimates}

In all model variants our choice of control variables to account for the background noise of residential mobility is based on and extends the estimation results of Tatsiramos (2006). Tatsiramos (2006) studied residential mobility of people over the age of 50 in several European countries using the ECHP. As the German contribution to the ECHP data set is an adjusted sample of the SOEP, we draw on those variables that proved statistically significant in explaining moves in Germany in the specification by Tatsiramos (2006). These include whether the respondent lost his spouse, experienced a health shock (disability, not the continuing status, $3.5 \%$ ), lives in a couple (77\%) and with children (4.3\%). In our specification we did not include liv-

\footnotetext{
${ }^{10}$ The underlying sample is smaller relative to the information given for $m_{i, t}^{c o}$ (874 cases) because a lagged time period is necessary for $\Delta r_{i, t}$.
} 
ing in an apartment and whether housing costs are a burden nor household wealth because we did not find appropriate panel information in the SOEP. In the estimation by Tatsiramos (2006), entering retirement proved an additional important determinant of moving behavior; we will naturally also include a retirement status dummy in our equations, but the dependent variables are different.

Other control variables are time dummies, indicators for East (mean of 30\%) and North West Germany (referring to the states of Sleswick-Holsatia, Hamburg, Bremen, Lower Saxony, and North Rhine-Westphalia; mean 38\%), loss of spouse $(0.53 \%)$, regular employment status of spouse $(9.5 \%)$, German nationality. Furthermore, the size of the home, the real rent, the change of household size as an integervalued variable, age squared, and the tenure in the current home (divided by 10 as a scaling device) are also controlled for. Note that some of the variables are not time-varying and therefore do not appear in fixed-effect specifications below.

\subsection{Housing consumption reductions through relocation}

The first part of our empirical analysis concerns the events of moving to a cheaper home and/or for cost reasons. In principle all men (between 55 and 75) are included here, irrespective of ever having switched into retirement or not.

For the binary dependent variables as defined before we use the following probability model in our panel context:

$$
\operatorname{Pr}\left(m_{i, t}^{s}=1 \mid \mathbf{x}\right)=\Lambda\left(\alpha_{i}^{s}+\mathbf{x}_{i, t}^{\prime} \beta^{s}\right), \quad i=1 \ldots N, \quad t=1 \ldots T_{i},
$$

where $s \in\{c h, c o\}$ indexes the different dependent variables and $\alpha$ are the unobserved individual-specific effects. Note that $\mathbf{x}$ contains some time-invariant variables as well as time dummies. The time dimension for this unbalanced panel varies between all theoretically possible values (1 to 19).

$\Lambda()$ is the logistic CDF, meaning that we have chosen a (panel) logit model instead of a probit model. For the probit class, a fixed-effects specification that does not suffer from the incidental parameters problem is not available. In contrast, for the panel logit model it is possible to use a conditional likelihood which does 
not depend anymore on the unit effects and which can be used to estimate the remaining parameters consistently. A random-effects specification requires relatively strong assumptions regarding the unobserved heterogeneity, and as a practical issue we encountered numerical problems with convergence of the random-effects logit estimator algorithm with our data. Using a fixed-effects approach also facilitates the comparison with a recent dynamic specification method as shown below. A standard Hausman test clearly rejects the pooled specifications in favor of (conditional) fixed effects: $\chi^{2}(18)=58.3, p=0.000$ for the $m_{i, t}^{c o}$ equation, and $\chi^{2}(18)=154.2, p=0.000$ for the $m_{i, t}^{\text {ch }}$ equation.

Note that units where all outcomes are the same (all zero or all one over time) do not contribute information to the conditional likelihood for the fixed-effects logit. Hence below we report sample sizes without those units for the fixed-effects specifications; this is a feature of the conditional fixed-effects model and should not be mistaken for an arbitrary sample selection.

In table 2 the results of our panel logit estimations with respect to the binary dependent variables of moving to a cheaper home or due to cost reasons are reported. Both variants include time dummies and further controls as mentioned in the notes. The variables "relative income change" and "relative leisure change" are constructed as interaction effects of the current income (or leisure amount) relative to the pre-retirement level multiplied with the retirement status dummy. They capture the changes occurring at retirement. These variables would be zero throughout for non-retiring households, but the variables are not time-constant in general.

The salient finding is that the retirement status clearly increases the probability of reducing housing consumption by either moving to a cheaper home or moving for (self-reported) cost reasons. As discussed in Section 2.3, in the case of $m^{\text {ch }}$ (move_cheaper) some confounding effects may be partly responsible for this result; but especially in the case of $m^{c o}$ (move_cost) this significant effect appears to contradict the life-cycle hypothesis. The higher amount of post-retirement leisure ("relative leisure change", included with a year's lag) indeed significantly tends to prevent the move to a cheaper home, but it does not have that effect on the selfreported "move for cost reasons". 
In contrast, the income effects are only significant in the move_cost equation, which is perhaps surprising. The negative effect of the past year's overall income level (irrespective of the retirement status) on the propensity to cut housing consumption by moving is expected. But it is noteworthy that the effects of relative income changes at retirement are estimated with a positive sign. Taking together the baseline overall income effect $(-2.36)$ and the additional effect after retirement (2.19) in the move_cost equation, the post-retirement income level would have almost no influence on the probability to move for cost reasons anymore. This partial result by itself appears consistent with the life-cycle hypothesis.

The coefficients in logit models are not quantitatively meaningful by themselves, and typically the marginal effects would be analyzed. Unfortunately, in a fixed-effect framework this is not directly possible as the level information is lost after purging the individual effects. A quantitative interpretation will be given for the different approach in Section 4.2 below.

The results reported so far were based on a static logit specification, where a dynamic dependency was only allowed indirectly through the variable of the past tenure in the home. Intuitively, however, having moved to a cheaper home (or for cost reasons) in the past year should negatively affect the probability of moving (again) in the current year. This would amount to a dynamic logit specification. The well-known econometric issue with that in a panel context is the incidental parameter problem which leads to biased estimates. A recent solution is the quasi-logit model (quadratic exponential) proposed by Bartolucci and Nigro (2010), which can be regarded as an approximate dynamic logit model allowing a conditional FE approach. The conditional distribution of the binary dependent variable in the model is given as

$$
\operatorname{Pr}\left(m_{i, t}^{s} \mid \alpha_{i}^{s}, X_{i}, m_{i, 0}^{s}, \ldots, m_{i, t-1}^{s}\right)=\frac{\exp \left(m_{i, t}^{s}\left(\alpha_{i}^{s}+\mathbf{x}_{i, t}^{\prime} \beta_{1}+m_{i, t-1}^{s} \gamma+e_{t}^{*}\left(\alpha_{i}, X_{i}\right)\right)\right)}{1+\exp \left(\alpha_{i}^{s}+\mathbf{x}_{i, t}^{\prime} \beta_{1}+m_{i, t-1}^{s} \gamma+e_{t}^{*}\left(\alpha_{i}, X_{i}\right)\right)}
$$

where $e_{t}^{*}$ is a correction term; in particular, for $t<T_{i}$ this correction term is approximately $e_{t}^{*} \approx 0.5 \gamma$ (see Bartolucci and Nigro, 2010, p. 724), where $T_{i}$ is the individual-specific final time period, and thus $\beta_{1}$ are (approximately) the only co- 
Table 2: Reducing housing consumption by moving (static)

\begin{tabular}{lcc}
\hline & move_cheaper, $m^{c h}$ & move_cost, $m^{c o}$ \\
\hline Retirement status & $0.81^{* *}$ & $1.97^{* *}$ \\
Relative income change $\times$ & 0.34 & 0.78 \\
retired, $t-1$ & 0.15 & $2.17^{*}$ \\
Relative leisure change & $-2.02^{* * *}$ & \\
retired, $t-1$ & 0.78 & 0.44 \\
Income level $(\log ) t-1$ & -0.43 & 1.29 \\
& 0.39 & $-2.36^{* * *}$ \\
Leisure level, $t-1$ & 0.06 & 0.91 \\
& 0.042 & -0.06 \\
Real rent (log) $t-1$ & $4.04^{* * *}$ & 0.067 \\
Tenure in home $t-1$ & 0.47 & $3.54^{* * *}$ \\
(years $/ 10$ ) & $2.52^{* * *}$ & 0.96 \\
Size of dwelling $t-1$ & 0.26 & 0.63 \\
& & \\
$N, \sum T_{i}$ & $0.026^{* * *}$ & $0.089^{* * *}$ \\
log likelihood & 0.006 & 0.019 \\
\hline
\end{tabular}

Notes: Panel logit estimates, FE - (conditional) fixed effects. Standard errors below estimates, two-sided significance levels denoted by ${ }^{* * *}(1 \%),{ }^{* *}(5 \%),{ }^{*}(10 \%)$. Definitions of variables (see also Section 4): "move_cheaper" - moved into cheaper home, "move_cost" - moved because of (self-proclaimed) cost reasons. Time dummies also included, as well as controls: age squared, loss of spouse, couple, change of household size, East, Northwest, disability status, employed spouse, unemployed, self-employed. 
efficients associated with the covariates $\mathbf{x}_{i, t}^{\prime}$.

We have applied that estimation approach to dynamic versions of the specifications of Table 2, and we report the estimates of $\gamma$ and $\beta_{1}$ in Table $3 .^{11}$ The lagged term appears quantitatively quite important but is significant only in the move_cheaper equation. The coefficient point estimates of the retirement status effect are reduced in both equations and are also estimated less precisely in this dynamic specification compared to the previous static one, which leads to a loss of statistical significance in the case of the move_cheaper equation. The other results remain qualitatively unchanged.

\subsection{Housing consumption pre- vs. post-retirement}

As a second empirical approach we also construct from our panel information a cross-sectional sample where only the men with an observed retirement event are included. For those individuals we define four relevant variables to be explained:

1. Rent paid after retirement, relative to pre-retirement levels. (Average levels over the observed time spans are used, expressed as growth rates from preto post-retirement, $g\left(r_{i}\right)$.)

2. Size of the dwelling after retirement, relative to pre-retirement levels. (Also growth of the average levels, $g\left(s_{i}\right)$.)

3. Incidence of move_cheaper events after retirement, relative to pre-retirement levels. (Absolute difference, normalized by the lengths of the observed time spans.)

4. Incidence of move_cost events after retirement, relative to pre-retirement levels.

The first variable growth of rent paid $g\left(r_{i}\right)$ directly measures the change of the cost of housing occurring around the retirement event. With the second variable growth

\footnotetext{
${ }^{11}$ We have used the DPB package for gretl to achieve this, see Lucchetti and Pigini (2015).
} 
Table 3: Reducing housing consumption by moving (dynamic)

\begin{tabular}{lcc}
\hline & move_cheaper, $m^{c h}$ & move_cost, $m^{c o}$ \\
\hline Lag of dependent variable & $-1.82^{* * *}$ & -1.52 \\
& 0.70 & 1.51 \\
Retirement status & 0.50 & $1.48^{*}$ \\
& 0.41 & 0.86 \\
Relative income change $\times$ & -0.21 & $3.25^{* *}$ \\
retired, $t-1$ & 0.94 & 1.64 \\
Relative leisure change & $-2.32^{* *}$ & 1.19 \\
retired, $t-1$ & 1.00 & 1.70 \\
Income level $(\log ) t-1$ & -0.39 & $-2.63^{* *}$ \\
& 0.48 & 1.05 \\
Leisure level, $t-1$ & 0.07 & -0.07 \\
& 0.052 & 0.085 \\
Real rent $(\log ) t-1$ & $4.40^{* * *}$ & $3.74^{* * *}$ \\
Tenure in home $t-1$ & 0.55 & 1.06 \\
(years $/ 10)$ & $2.72^{* * *}$ & $3.88^{* * *}$ \\
Size of dwelling $t-1$ & 0.33 & 0.64 \\
& & \\
$N, \sum T_{i}$ & $0.033^{* * *}$ & $0.092^{* * *}$ \\
log likelihood & 0.008 & 0.022 \\
\hline
\end{tabular}

Notes: Quadratic-exponential quasi-logit panel estimation, see Bartolucci and Nigro (2010); estimates for $t<T_{i}$ are shown, see the text. Standard errors below estimates, two-sided significance levels denoted by ${ }^{* * *}(1 \%),{ }^{* *}(5 \%),{ }^{*}(10 \%)$. Definitions of variables (see also Section 4): "move_cheaper" - moved into cheaper home, "move_cost" - moved because of (self-proclaimed) cost reasons. Time dummies also included, as well as controls: age squared, loss of spouse, couple, change of household size, East, Northwest, disability status, employed spouse, unemployed, self-employed. 
of the size $g\left(s_{i}\right)$ we attempt to control for some of the confounding effects: for example a larger house in a rural area might be cheaper, yet yield higher utility than a small expensive city apartment. However, this relationship is still ambiguous, because a larger apartment in a bad neighborhood might also provide lower utility than a smaller apartment in a good neighborhood. The last two measures are somewhat unusual as they are based on the differences of the averages of binary variables. We include them for comparison with the panel-econometric results in Section 4.1 , but notice that after differencing the normalized fractions these variables are not binary anymore. Also, in order to make the directions of the effects comparable with the first two housing consumption measures we present the negative of the influences on the changes of $m^{c h}$ and $m^{c o}$, such that a positive coefficient always means a positive effect on housing consumption.

In Table 4 the cross-sectional estimates for these four variables are reported. The leisure change relative to pre-retirement levels (second row) turns out as significant only for the incidence of moves due to cost reasons (last column) with the expected sign. In contrast, the income effect at retirement (first row) is significant for the cardinal measures of rent growth and size growth. The positive signs of the coefficients means that a larger income drop at retirement translates into a larger reduction of housing consumption, even after controlling for leisure changes, which contradicts the life-cycle hypothesis as outlined in Section 2.

While we have marked the significance levels in this paper corresponding to two-sided tests, the test of the life-cycle hypothesis is usually a one-sided setup where the alternative hypothesis postulates a co-movement. From that perspective all mentioned effects in Table 4 and earlier tables are significant at least at a 5\% level. On the other hand, the magnitude of the effect is certainly small: For example, a typical drop of income after retirement by $30 \%$ would lead to a reduction of the real rent growth by only 3 percentage points on average. In general, remember that the estimates only refer to non-home owners and as far as they contradict the life-cycle model they are likely to be larger than for home owners. 
Table 4: Estimation results in the cross-section sample of retirers

\begin{tabular}{|c|c|c|c|c|}
\hline & $g\left(r_{i}\right)$, rent & $g\left(s_{i}\right)$, size & $\begin{array}{c}\text { change of } m^{c h} \\
\text { (negative) }\end{array}$ & $\begin{array}{c}\text { change of } m^{c o} \\
\text { (negative) }\end{array}$ \\
\hline Real income growth & $\begin{array}{c}0.11^{* *} \\
0.052\end{array}$ & $\begin{array}{c}0.088^{*} \\
0.049\end{array}$ & $0.026 \times 10^{-3}$ & $\frac{0.27 \times 10^{-3}}{0.24}$ \\
\hline Leisure growth & $\begin{array}{c}0.015 \\
0.054\end{array}$ & $\begin{array}{c}-0.014 \\
0.048\end{array}$ & $0.040 \times 10^{-3}$ & $0_{0.26}^{0.44^{*}} \times 10^{-3}$ \\
\hline $\begin{array}{l}\text { Real inc. level } \\
\text { (pre-ret.) }\end{array}$ & $\begin{array}{l}0.0077^{* * *} \\
0.0020\end{array}$ & $\begin{array}{l}0.0018^{* *} \\
0.00084\end{array}$ & - & - \\
\hline $\begin{array}{l}\text { Leisure level } \\
\text { (pre-ret.) }\end{array}$ & - & $\begin{array}{c}-0.76^{*} \\
0.46\end{array}$ & - & $\begin{array}{l}0.013^{* *} \\
0.0052\end{array}$ \\
\hline Rent level (pre-ret.) & $\begin{array}{l}-0.077^{* * *} \\
0.019\end{array}$ & $\begin{array}{l}0.012 \\
0.008\end{array}$ & $-0.047^{*} \times 10^{-3}$ & - \\
\hline $\begin{array}{l}\text { Dwelling size } \\
\text { (pre-ret.) }\end{array}$ & - & $\begin{array}{l}-0.31^{* * *} \\
0.07\end{array}$ & - & - \\
\hline HH growth change & $\begin{array}{l}6.27^{* *} \\
2.81\end{array}$ & $\begin{array}{l}13.8^{* * *} \\
4.6\end{array}$ & $\begin{array}{c}0.036^{*} \\
0.022\end{array}$ & - \\
\hline $\begin{array}{l}\text { HH growth } \\
\text { (pre-ret.) }\end{array}$ & - & $\begin{array}{l}5.21^{* *} \\
2.14\end{array}$ & $\begin{array}{l}0.021^{*} \\
0.011\end{array}$ & - \\
\hline $\begin{array}{l}\text { Further significant } \\
\text { controls }\end{array}$ & unemployed & $\begin{array}{c}\text { German } \\
\text { citizen, } \\
\text { employed } \\
\text { spouse }\end{array}$ & $\begin{array}{l}\text { German } \\
\text { citizen, early } \\
\text { retirement }\end{array}$ & unemployed \\
\hline$N$ & 314 & 314 & 287 & 308 \\
\hline$R^{2}$ & 0.224 & 0.231 & 0.052 & 0.085 \\
\hline
\end{tabular}

Notes: OLS estimates in a cross-section consisting of men with an observed retirement event at any time in the underlying sample. Heteroskedasticity-robust standard errors in parentheses, two-sided significance at 10/5/1 per cent indicated with ${ }^{* *} / * * *$. Only control variables with a $p$-value below 0.2 and a constant have been retained (" - " denotes a dropped variable with $p>0.2$ ). 


\section{Conclusions}

In this paper we have tried to shed new light on the retirement-consumption puzzle. We have argued that predictions of the life-cycle hypothesis must be interpreted conditionally on the large increase of available leisure at retirement, a theoretical insight which is often neglected in the literature. Our analysis is focussed on the consumption of housing, based on the assumption that housing enters the utility function as a complement to leisure, and thus under the life-cycle hypothesis it should typically be reduced less than other consumption goods at retirement.

Based on the behavior of 55 to 75-year olds in the German SOEP we first found that (foreseeable) retirement events have a significant effect on moving to cheaper homes and/or moving due to self-reported cost reasons in a panel econometric analysis. We then also found for the cross-section of retirees that the income drop at retirement has a (negative) effect on housing consumption as measured by rent growth and dwelling size growth. As suggested by our theoretical framework we controlled for the amount and change of available leisure time which turned out to be significant in some specifications.

These findings imply that the smoothing hypothesis of the life-cycle model of consumption and saving may be violated for the large subgroup of non-home owners in Germany. This is interesting insofar as the conventional wisdom is that "faced with large income changes, households seem to react in line with the PIH" (Fuchs-Schündeln and Hassan 2015, p. 28, who do not explicitly mention the retirement consumption puzzle, however).

In principle our evidence confirms the existence of a retirement-consumption puzzle, contrary to some recent statements in the literature. As the leading explanations of this puzzle are given by behavioral economic theories, aggregate models would have to allow for heterogeneous agents not only in the sense of different endowments and shocks, but also in the sense of different behavioral rules in order to capture these aspects of reality.

However, some qualifications of our results should be noted. First, our sample was deliberately restricted to non-homeowners, and we expect the life-cycle model 
to be more accurate for home owners due to their systematically higher cumulated savings that financed their home in the first place. Secondly, in some specifications we did not find effects of current income after retirement. Finally, the elasticity with respect to housing expenditure growth appears to be quite small. Therefore, we do not believe that a general conclusion can be drawn on whether the life-cycle model is still appropriate as an approximation, instead such a decision should depend on the characteristics of the respective application.

\section{References}

AgUiAR, M., AND E. HURST (2005): “Consumption versus Expenditure," Journal of Political Economy, 113(5), 919-948.

Aguila, E., O. Attanasio, And C. MeghiR (2011): “Changes in Consumption at Retirement: Evidence from Panel Data," Review of Economics and Statistics, 93(3), 1094-1099.

AKerlof, G. A. (2002): “Behavioral Macroeconomics and Macroeconomic Behavior," American Economic Review, 92(3), 411-433.

(2007): “The Missing Motivation in Macroeconomics," American Economic Review, 97(1), 5-36.

Attanasio, O. P., And M. Browning (1995): “Consumption over the Life Cycle and over the Business Cycle," American Economic Review, 85(5), 1118-37.

BANKS, J., R. Blundell, And S. TANNER (1998): "Is There a Retirement-Savings Puzzle?," American Economic Review, 88(4), 769-88.

BARRO, R. J. (1974): “Are Government Bonds Net Wealth?," Journal of Political Economy, vol 82, no 6, 1095-1117.

Bartolucci, F., And V. Nigro (2010): “A Dynamic Model for Binary Panel Data with Unobserved Heterogeneity Admitting a root-n-Consistent Conditional Estimator," Econometrica, 78(2), 719-733.

Baxter, M., And U. J. Jermann (1999): “Household Production and the Excess Sensitivity of Consumption to Current Income," American Economic Review, 89(4), 902-920.

Benartzi, S., AND R. H. Thaler (2007): "Heuristics and Biases in Retirement Savings Behavior," Journal of Economic Perspectives, 21(3), 81-104.

Bernheim, B. D., J. SKINNER, AND S. WEINBERG (2001): "What Accounts for the Variation in Retirement Wealth among U.S. Households?," American Economic Review, 91(4), 832-57. 
Beznoska, M., And V. STeiner (2012): "Does Consumption Decline at Retirement? Evidence from Repeated Cross-Section Data for Germany," Discussion Paper 14, Free University of Berlin School of Business \& Economics.

BLAU, D. M. (2008): "Retirement and Consumption in a Life Cycle Model," Journal of Labor Economics, 26, 35-71.

CAmpbell, J. Y., and N. G. MANKIW (1990): "Permanent Income, Current Income, and Consumption," Journal of Business E Economic Statistics, 8(3), 265-79.

Friedman, M. (1957): A Theory of the Consumption Function. Princeton U Press.

FUCHS-SCHÜNDELN, N., AND T. A. HASSAN (2015): “Natural Experiments in Macroeconomics," NBER Working Paper 21228.

HAider, S. J., AND M. STEPHENS (2007): "Is There a Retirement-Consumption Puzzle? Evidence Using Subjective Retirement Expectations," The Review of Economics and Statistics, 89(2), 247-264.

Heckman, J. J. (1974): “Life Cycle Consumption and Labor Supply: An Explanation of the Relationship Between Income and Consumption Over the Life Cycle," American Economic Review, 64(1), 188-194.

Hurd, M. D., And S. Rohwedder (2008): “The Retirement Consumption Puzzle: Actual Spending Change in Panel Data," NBER Working Papers 13929, National Bureau of Economic Research, Inc.

HURST, E. (2008): "The Retirement of a Consumption Puzzle," NBER Working Papers 13789, National Bureau of Economic Research, Inc.

KROH, M. (2009): “Documentation of Sample Sizes and Panel Attrition in the German Socio Economic Panel (SOEP) (1984 until 2008)," Data Documentation 47, DIW.

LAIBSON, D. (1997): “Golden Eggs and Hyperbolic Discounting," The Quarterly Journal of Economics, 112(2), 443-77.

Lucchetti, R., AND C. Pigini (2015): “DPB: Dynamic Panel Binary data models in Gretl," gretl Working Paper 1, Università Politecnica delle Marche.

LÜHRMANN, M. (2010): “Consumer Expenditures and Home Production at Retirement: New Evidence from Germany," German Economic Review, 11, 225-245.

LUNDBERG, S., R. STARTZ, AND S. STILLMAN (2003): “The retirement-consumption puzzle: a marital bargaining approach," Journal of Public Economics, 87(5-6), 11991218.

MOdigliani, F., AND R. H. BRUmberG (1954): “Utility analysis and the consumption function: an interpretation of cross-section data," in Post-Keynesian Economics, ed. by K. K. Kurihara, pp. 388-436. Rutgers University Press, New Brunswick, NJ.

O’Donoghue, T., And M. RABin (1999): "Procrastination in preparing for retirement," in Behavioral Dimensions of Retirement Economics, ed. by H. Aaron, chap. 4, pp. 125-56. Brookings Institution Press. 
REIS, R. (2006): “Inattentive consumers," Journal of Monetary Economics, 53(8), 17611800.

Scholz, J. K., A. Seshadri, And S. Khitatrakun (2006): “Are Americans Saving "Optimally" for Retirement?," Journal of Political Economy, 114(4), 607-643.

SCHWERDT, G. (2005): "Why Does Consumption Fall at Retirement? Evidence from Germany," Economics Letters, 89(3), 300-305.

SHEFrin, H. M., AND R. H. ThALER (1988): “The Behavioral Life-Cycle Hypothesis," Economic Inquiry, 26(4), 609-43.

SMITH, S. (2006): “The Retirement-Consumption Puzzle and Involuntary Early Retirement: Evidence from the British Household Panel Survey," Economic Journal, 116(510), C130-C148.

SOEP (2013): "Socio-Economic Panel, data for years 1984-2012, version 29," doi:10.5684/soep.v29; http:/ /www.diw.de/soep.

Stancanelli, E., and A. Van Soest (2012): "Retirement and Home Production: A Regression Discontinuity Approach," American Economic Review, Papers and Proceedings, 102(3), 600-605.

TAtsiramos, K. (2006): “Residential Mobility and Housing Adjustment of Older Households in Europe," IZA DP 2435, Forschungsinstitut zur Zukunft der Arbeit / Institute for the Study of Labor.

\section{A Institutional information Germany}

It may be useful to summarize some characteristics related to the German housing market.

There is a means-tested subsidy called "housing money": Wohngeld. For registered unemployed it was subsumed under general unemployment benefits and social assistance (ALG II) starting in 2005 with the Hartz reform. Those who receive Wohngeld are already in an "appropriate" apartment, so they should not have any reason to move to a cheaper home. In any case, the subsidy is part of the measured household income.

The time that must elapse after the tenant announces his desire to end a rent contract until the contract legally ends had been subject to another reform: since June 2005 it is generally only 3 months for tenants, whereas until August 2001 it was up to 12 months dependent on the past contract duration. Between September 2001 and May 2005 it depended on whether it was an old contract (old rules) or 
new contract (new rules). In contrast, for landlords it has always depended on the contract duration and mirrors the old rules for tenants (up to 12 months).

Here is a summary of historical regulations of rent increases applying to apartments which are not "price constrained" (without Mietpreisbindung -note that there are also apartments where construction was state-subsidized and rents are therefore price constrained). A very recent reform (in 2015) is irrelevant for our sample.

- Within 3 years the rent in an existing contract can only grow by $20 \%$ (not counting recurrent costs like staircase cleaning or elevator maintenance etc. (Betriebskosten), or modernization expenses.

- The increased rent may not exceed the "local standard comparison rent" (LSCR, ortsübliche Vergleichsmiete) which is determined based on official surveys.

- Raising the rent requires mandated approval by the tenant; if the tenant does not grant this, the landlord must sue the tenant to legally get the mandated approval, and prove in court that the rent increase meets legal requirements (e.g. conforms to LSCR).

- A contract with a new tenant may not specify a rent exceeding the LSCR by $50 \%$, but within this limit the landlady is in principle free to choose which amount she demands.

\section{B Further information on the variables}

\section{B.1 The retirement event}

The fraction of observations with a retirement event is $1.8 \%$, where the construction of the retirement event dummy is actually not trivial: In the SOEP questionnaire, respondents who have entered retirement recently (since last year's survey) can be identified with a combination of questions (i) on the termination of the last job within the past or the current year and (ii) on the reason for leaving that job. This information is available and, to the best of our knowledge, reliable since the survey year 1993. We define the variable "entering retirement" as taking the value 1 if the 
respondent reports the termination of his job since last year's questionnaire and old-age pension or early retirement as the reason for this event. Entering an earlyretirement scheme is also considered in an additional variable "early retirement" which, correspondingly, takes the value 1 if the respondent reports the termination of his job since last year's questionnaire and early retirement as the reason for this event. We interpret "early retirement" as an interaction variable which covers the additional effect of entering retirement rather unforeseeably and therefore unanticipatedly. In the SOEP questionnaire, the early retirement information is available until the year 1998 only. Hence the variable is always zero afterwards. However, if a respondent reports a (regular) retirement event in two subsequent years, we interpret the first event as an early retirement and set the respective variable to 1 .

\section{B.2 Distributions of control variables}

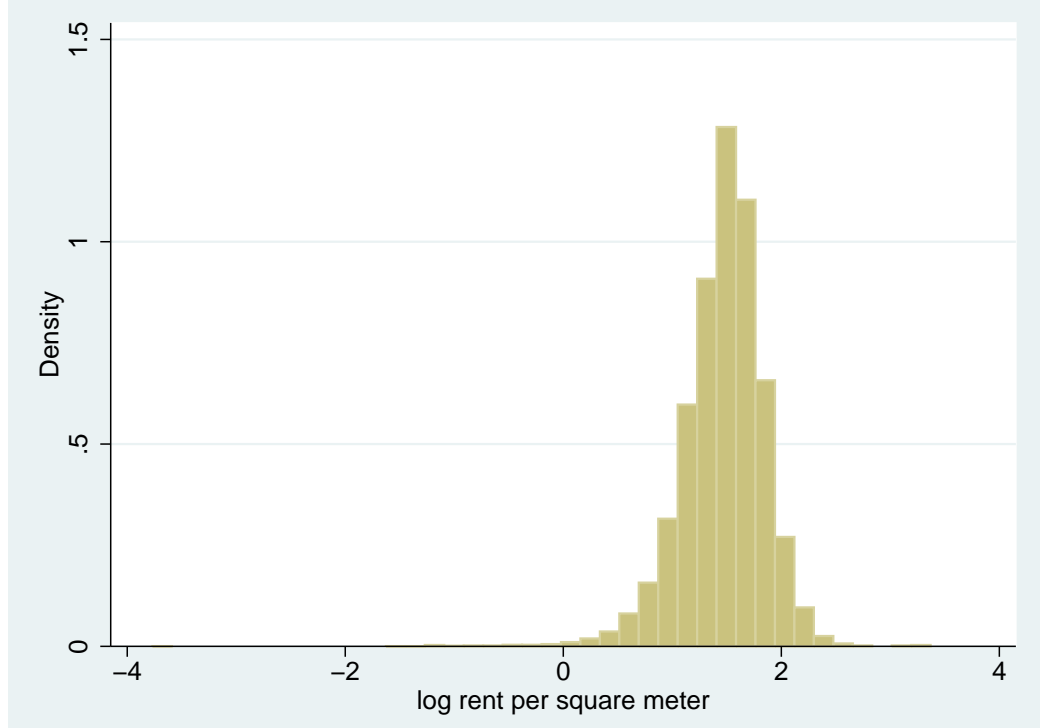



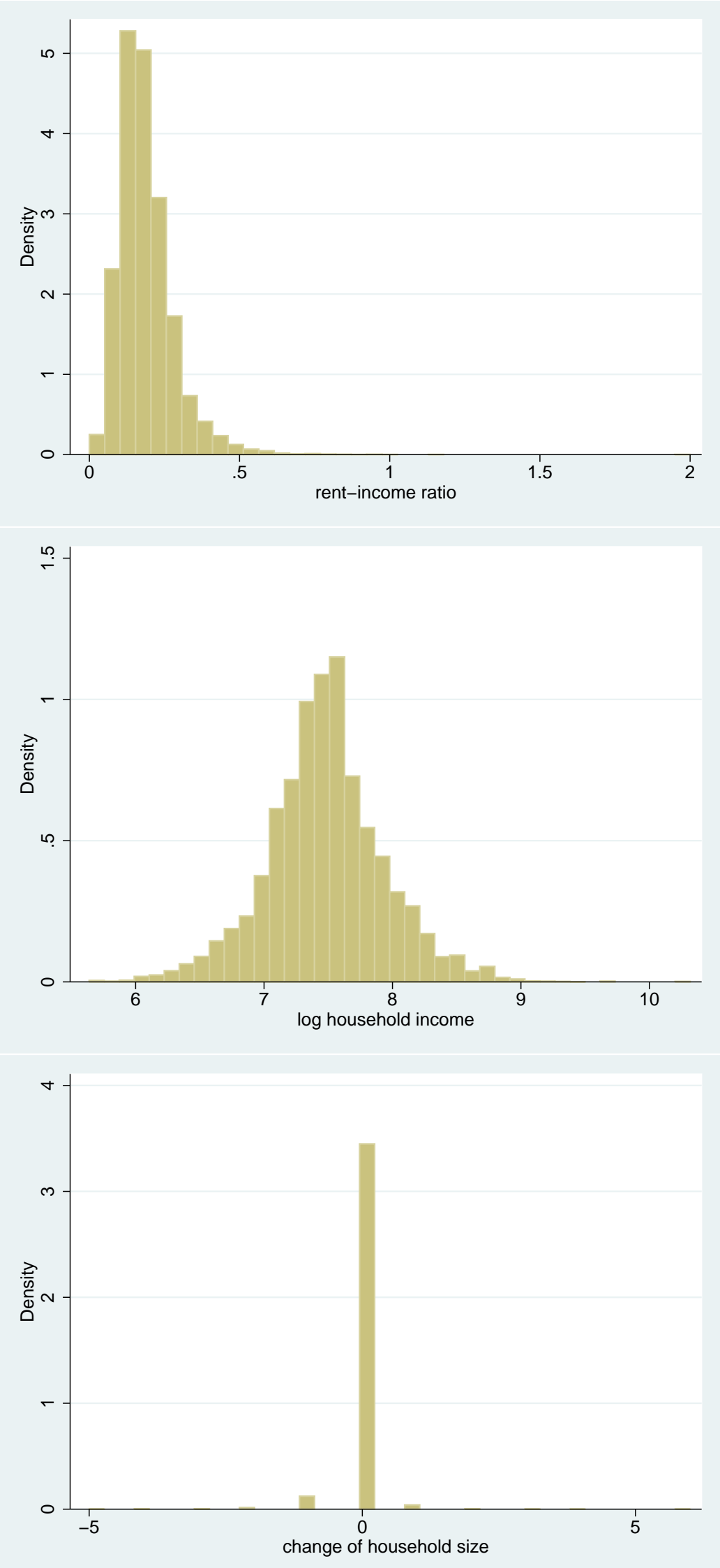

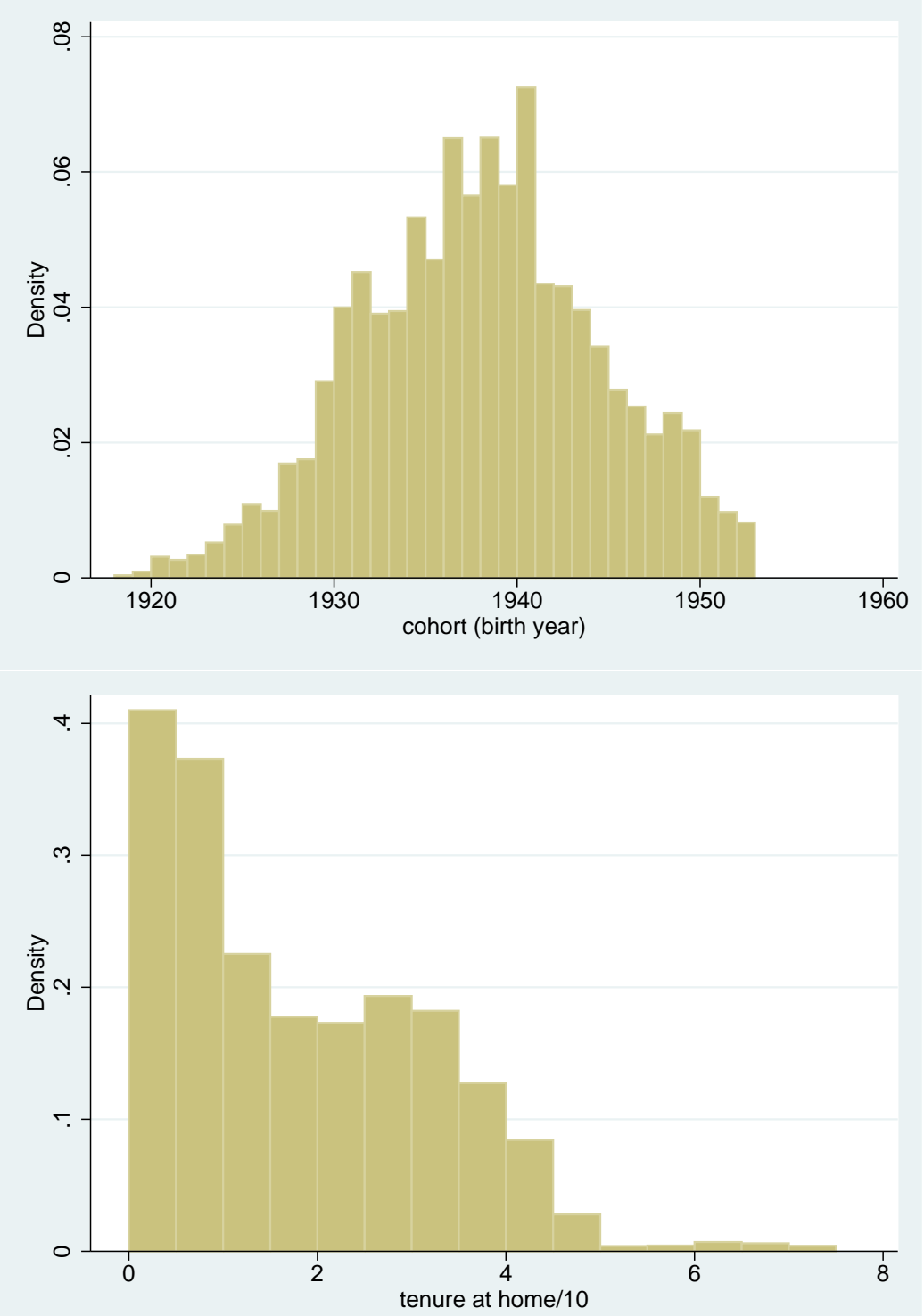